Nurbek Umirov Norbutayevich, doctoral student, Karshi state university E-mail:18021988umirov@gmail.com Fayzulla Nurkulov Nurmuminovich, doctor of Technical Sciences, Tashkent Scientific Research Institute of Chemical Technology, Uzbekistan, Tashkent region, Zangiata district, $\mathrm{P} / \mathrm{o}$ Shuro-bazaar Abdulakhat Djalilov Turopovich, doctor of chemistry, academic, director of the Stat Unitary Enterprise Tashkent Scientific Research Institute of Chemical Technology, Uzbekistan, Tashkent region, Zangiata district, P / o Shuro-bazaar

\title{
DEVELOPMENT OF GASOLINE COMPOSITION COMPOUNDED WITH THE USE OF ANTI-KNOCK MODIFIER A-18
}

Abstract. The ecological safety of the use of anti-knock modifier A-18 in systems in the oil and gas-chemical industry is shown and their efficiency is determined.

Keywords: anti-knock modifier, amyl, isobutyl, n-propyl and ethyl, oxygen-containing modifiers.

Introduction: an Increase in the octane number of gasoline to the required level is possible either by expanding the production of high-octane hydrocarbon fuel components through optimization and modernization of oil refining schemes at the refinery, or by selecting new non-toxic octane additives and components of non-oil origin [1].

Oxygenates are called oxygen-containing organic compounds that act as antidetonators. Their use in concentrations of several percent allows us to consider them no longer additives, but components of motor fuel. The main advantage of oxygenates is the possibility of expanding the resources of motor fuels at the expense of raw materials of non-oil origin.

The use of fuels containing ethanol as a high-octane additive has been successfully implemented worldwide. In USA from 1978 to richen the fuel gasohol, which contains $10 \%$ ethanol. ASTM standard developed by the national Commission on alcoholic fuels of the
United States, setting '! gasohol for the following indicators: the density of $730-760 \mathrm{~kg} / \mathrm{m}^{3}$, the limits of boiling $25-210^{\circ} \mathrm{C}$, calorific value of $41.9 \mathrm{MJ} / \mathrm{kg}$, heat of vaporization $465 \mathrm{MJ} / \mathrm{kg}$, saturated vapor pressure $\left(38^{\circ} \mathrm{C}\right) 55-110 \mathrm{kPa}$, viscosity $\left(40^{\circ} \mathrm{C}\right) 0,6 \mathrm{~mm}^{2} / \mathrm{s}$, the stoichiometric factor $14 \mathrm{In}$ Sweden and Finland is operated gasoline E85, which includes $85 \%$ ethanol. In Russia, OAO VNIINM together with JSC "AVTOVAZ" were tested gasoline containing 5-10\% ethanol, the results of which gasoline with the addition of $5 \%$ ethanol has been approved for use in automotive vehicles, but has not yet received wide distribution.

Ethanol, like all high-octane additives, has its drawbacks:

- resence of traces of water;

- like all alcohols, it has increased corrosion activity, depending on the water content and the molecular weight of alcohol (the greater the molecular weight of alcohol, the less aggressive it is [2-3]. 
The introduction of alcohol fuel appropriate modifiers and stabilizers can overcome the difficulties. The greatest influence on the delamination of alcohol gasoline has a water content. To ensure the stability of gasoline with alcohols in the production, storage and use it is necessary: to prevent the ingress of water into them; to use stabilizing additives or, in other words, co-solvents, homogenizing the gasoline-water-alcohol system [4].

As stabilizers of gasoline-alcohol mixtures it is proposed to use: aliphatic alcohols C3 - C2 normal and branched structure, phenols, allylacetate, ethers and esters and their organometallic derivatives, ketones, amines, surfactants, and glycols and their ethers, aldehydes, catali, acetals, acylcarbene, carboxylic acids and mixtures of these compounds. The addition of stabilizers prevents the stratification of alcohol-containing gasoline to a temperature of $-40-23^{\circ} \mathrm{C}[5]$.

Good and at the same time cheap stabilizer are fusel oils that provide homogeneity of fuel at temperatures above $-25^{\circ} \mathrm{C}$.

It should be noted that fuels comprising more than $40 \%$ vol. ethanol, have the required phase stability without prior dehydration of alcohol and the introduction of stabilizers.

When used in the composition of the fuel composition of watered ethanol to prevent delamination, stabilizers should be introduced (higher alcohols, aromatic amines, esters, ketones, So the addition of 2.5-3.0\% Isobutanol ensures the stability of the gasoline-ethanol mixture containing 5\% water at temperatures up to $-20^{\circ} \mathrm{C}$. [6].

\section{Experimental part.}

The motor method was used to determine the octane number at the unit UIT-65 allowing to change the compression ratio from 4 to 9 , where the detonation resistance of the studied gasoline is compared with the reference samples at a temperature of the combustible mixture of $150{ }^{\circ} \mathrm{C}$ and a rotational speed of $900 \mathrm{~min}$-The detonation resistance is determined by the research method at a temperature of the combustible mixture of $25-35^{\circ} \mathrm{C}$ (the mixture is not heated) and a rotational speed of $600 \mathrm{~min}-1$. Since the determination of the detonation resistance by the motor method takes place under more severe conditions, the result will be slightly lower than it would have been obtained by the determination by the research method In both cases, after the heating of the engine, the compression degree gradually increases until the detonation of a certain standard intensity determined by the scale of the detonation index.Also, the octane number can be approximately calculated by the formulas obtained value corresponds approximately to the octane number determined by the research method.;

$$
O \Psi=120-2\left(\frac{t_{c p}-58}{5 p}\right),
$$

where $t_{c p}$ - the average temperature of the distillation fuel

$$
t_{c p}=\frac{t_{H \kappa}+t_{\kappa \kappa}}{2}
$$

$t_{н \kappa}$ - initial boiling point fuel; $t_{\kappa \kappa}$ - the temperature of the end boiling point of the fuel; $p_{20}$ is the density of fuel at $20^{\circ} \mathrm{C}, \mathrm{g} / \mathrm{cm}^{3}$

\section{Results and discussion.}

In this paper, octane-boosting modifier synthesized on the basis of amyl, isobutyl, n-propyl and ethyl, oxygen-containing organic compounds were studied. the Reaction was carried out in a $500 \mathrm{ml}$ flask equipped with a reverse refrigerator for $30 \mathrm{~min}$ utes at a temperature of +8 to $+18^{\circ} \mathrm{C}$.

Octane-boosting modifier is applied by light car. One of the most effective octane oil system modifier is the $\mathrm{A}-18$ modifier

In recent years, a promising direction-the production and consumption of harmless (environmentally friendly) high-octane additives instead of IES-is successfully developing. Figure-1.

Compared to the graph, the octane growth shown in figure 1 seemed to be the best. The correct fraction of gasoline was used. The maximum increase in the number of octanes was changed to 18 units by the method of the octane number of the motor (ONM) 
and 18 units according to the method of research octane number(ONR). It should be noted that the addition of the a-18 modifier To the concentration of up to $2 \%$ led to the fact that the increase in the octane content of gasoline was the highest.As the concentration increased, the number of octanes decreased.

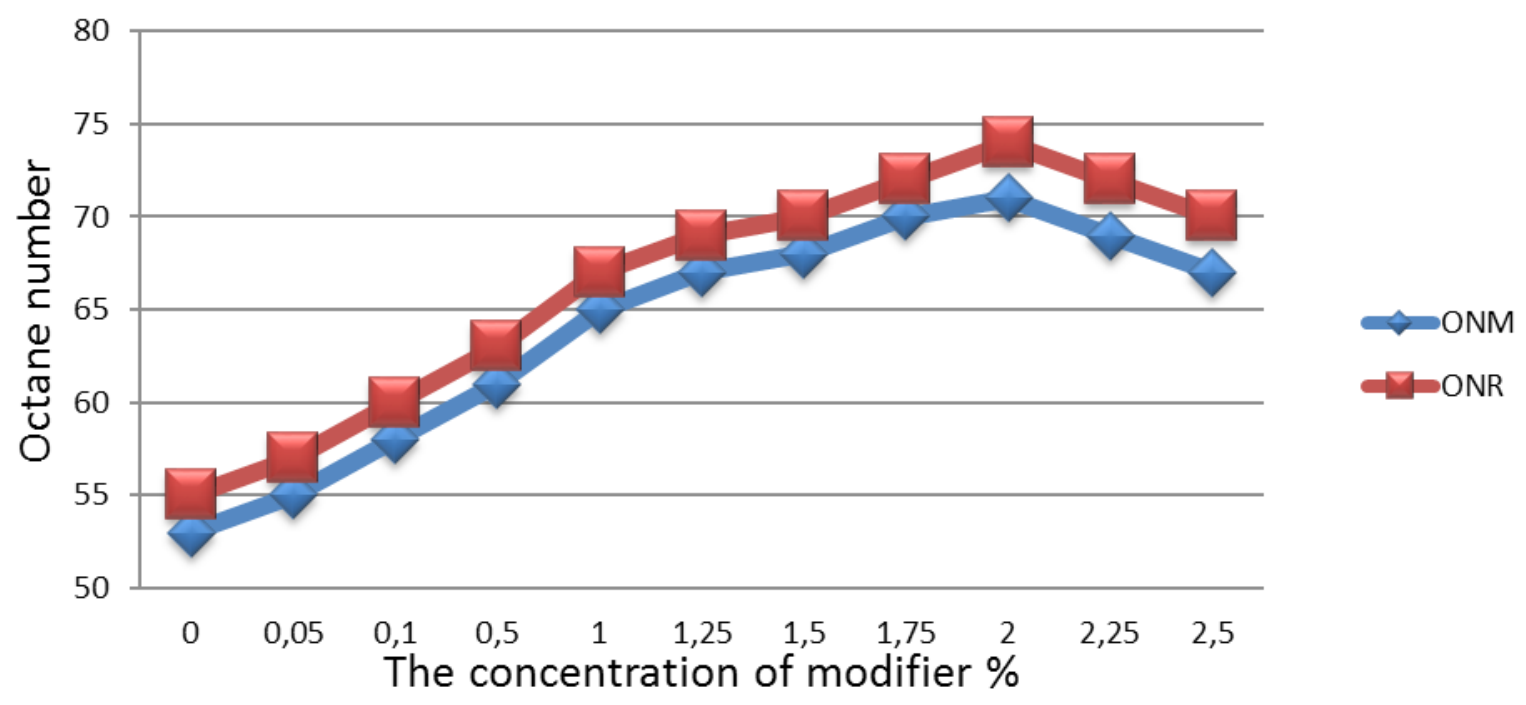

Figure 1 Change in the number of octanes when adding A-18 modifier in direct distillation of gasoline

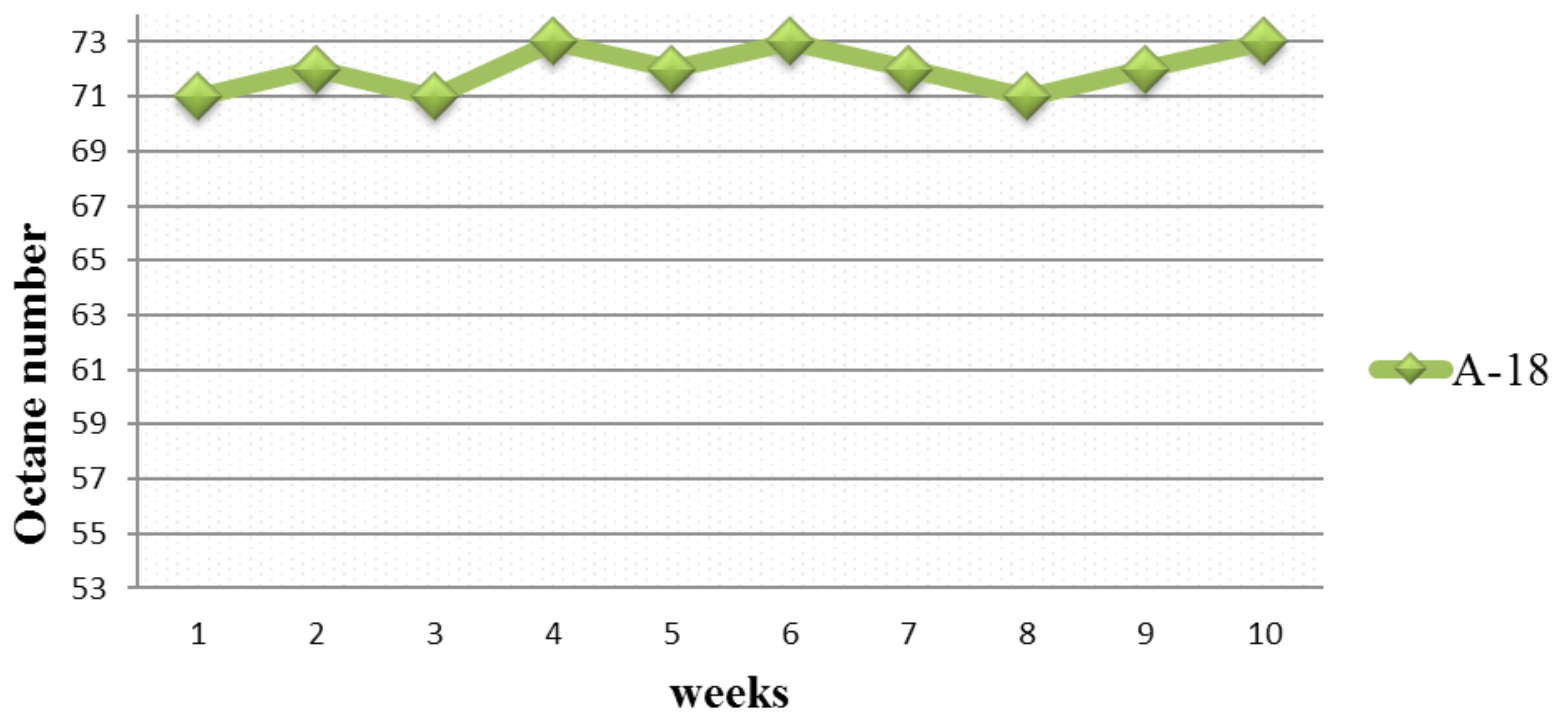

Figure 2. Storage stability of octane-boosting modifier

With the addition of the a-18 modifier to the creased by 1-2 units. The modifier we offer keeps feather distillation of gasoline 10 weeks waiting for the number of octanes, the number in gasoline de- long time.

\section{References:}

1. Developed GOST R52201-2004 - "Ethanol motor fuel for automotive engines with forced ignition. Bensaali, which operates from 1 July 2004.

2. Mirom W.L., Ragazzi R. A. //SAE Techn. Pap. Ser. 1986.- No. 860530.- 6 p. 
3. Black F. // SAE Techn. Pap. Ser. 1991.- No. 912413.- P. 1-30.

4. Ivanov P. V., Onoychenko S.I., Emelyanov V. E. Automobile fuel: Bhepat today, tomorrow. Analyte. review.-M.: 2001.

5. Kaminsky E. F. Ecological characteristics of motor fuels and new technologies for their provision.-M.Oil and gas,- P. 10-11.

6. Danilenko, Tatyana Viktorovna Development of fuel compositions of Gasoline with the addition of aliphatic alcohols Dis. ... kand. That science.-M.: RGB, 2005. 